\title{
Photocatalytic Degradation of Organic Pollutants: The Case of Conductive Polymer Supported Titanium Dioxide $\left(\mathrm{TiO}_{2}\right)$ Nanoparticles: A Review
}

\author{
Tigabu Bekele Mekonnen ${ }^{1,}$, Abi Tadesse Mengesha ${ }^{2}$, Hirpo Hinsene Dube ${ }^{3}$ \\ ${ }^{1}$ Department of Chemistry, Mekdela Amba University, Tuluawuliya, Ethiopia \\ ${ }^{2}$ Department of Chemistry, Haramaya University, Haramaya, Ethiopia \\ ${ }^{3}$ Department of Chemistry, Debrebrhan University, Ethiopia \\ Email address: \\ tgbekele19@gmail.com (T. B. Mekonnen), abi92003@yahoo.com (A. T. Mengesha), hirpohinsene@gmail.com (H. H. Dube) \\ ${ }^{*}$ Corresponding author
}

\section{To cite this article:}

Tigabu Bekele Mekonnen, Abi Tadesse Mengesha, Hirpo Hinsene Dube. Photocatalytic Degradation of Organic Pollutants: The Case of Conductive Polymer Supported Titanium Dioxide $\left(\mathrm{TiO}_{2}\right)$ Nanoparticles: A Review. Nanoscience and Nanometrology.

Vol. 7, No. 1, 2021, pp. 1-13. doi: 10.11648/j.nsnm.20210701.11

Received: January 28, 2021; Accepted: March 17, 2021; Published: April 7, 2021

\begin{abstract}
In recent years development of different type of industries are enlarged and these industries are connected with the discarding of organic pollutants which are harmful to aquatic system and the human health. The presence of those organic pollutants in the aquatic system can result in pollution of wastewater which affects the ecosystem. Therefore, the removals of pollutants have become an ecological concern and they are vital for the environmental sustainability. Many practices have been widely applied in the treatment of organic effluent such as biological treatment, reverse osmosis, ozonation, filtration, adsorption on solid phases, incineration, and coagulation. However, each of the methodologies has its own advantages and limitations. The recent research demonstrates that advanced oxidation processes (AOPs) based on photocatalysts are valuable and this method benefits complete mineralization of organic molecules into nontoxic $\mathrm{CO}_{2}$ and $\mathrm{H}_{2} \mathrm{O}$ at the atmospheric conditions by generating active species such as hydroxyl radicals $(\bullet \mathrm{OH})$ which can remove even non-biodegradable organic compounds from wastewater. These review papers give an overview of the enhanced photocatalytic activities of titanium dioxide $\left(\mathrm{TiO}_{2}\right)$ based photocatalyst. An effort has also been made to give an overview of expedient photocatalytic activity of these supported nanoparticles for their potential application in environmental remediation. In this review article also, various methods used to enhance the photocatalytic characteristics of $\mathrm{TiO}_{2}$ including doping, coupling and other supporting are discussed. It is observed that the degradation of dyes depends on several parameters like $\mathrm{pH}$, catalyst load, dye concentration, reaction temperature and scavengers on the degradation of dyes.
\end{abstract}

Keywords: Nanotechnology, Conducting Polymers, Nanoparticles, Photocatalysis, Photodegradation, $\mathrm{AOPs}_{1} \mathrm{TiO}_{2}$

\section{Introduction}

During the past several decades, fast and relatively uncontrolled population growth and also industrial, agricultural and technological developments have adversely affected the environment and human health. Especially wastewater effluents of industrial manufacturing companies contain toxic organic compounds [1]. Dyes are a well-known source of environmental pollution and therefore their removal from waste water receives increasing attention. They are generally resistant to light, water, oxidizing agents and many chemicals and therefore difficult to degrade once released into the aquatic systems. Azo dyes are the largest and most versatile class of organic dye-stuffs. These contain one or more azo bonds $(-\mathrm{N}=\mathrm{N}-)$ as a chromophore group in association with aromatic structures containing functional groups such as $-\mathrm{OH}$ and $-\mathrm{SO}_{3} \mathrm{H}$. The complex aromatic structures of azo dyes make them more stable and more difficult to remove from the effluents discharged into the water bodies [2]. A number of physical, chemical and biological techniques had been reported for the treatment of all types of dyes with limited success. 
For the removal of dye pollutants, traditional physical techniques (adsorption on activated carbon, ultrafiltration, reverse osmosis, coagulation by chemical agents, ion exchange on synthetic adsorbent resins, etc.) can generally be used efficiently. Nevertheless, they are nondestructive, since they just transfer organic compound from water to another phase, thus causing secondary pollution. Consequently, regeneration of the adsorbent materials and post-treatment of solid-wastes, which are expensive operations are needed [3, 4]. Due to the large amount of aromatics present in dye molecules and the stability of modern dyes, conventional biological treatment methods (microbiological or enzymatic decomposition and biodegradation) are ineffective for decolorization and/or degradation [5]. Furthermore, the majority of dyes is only adsorbed on the sludge and is not degraded [6]. Chlorination and ozonation are also being used for the removal of certain dyes but at slower rates as they have often high operating costs [7]. These are the reasons why advanced oxidation processes (AOPs) have been developed during the last decade since they are able to deal with the problem of dye destruction in aqueous systems.

The most important among those advanced oxidation processes is called heterogeneous photocatalytic oxidation which is often referred to as photocatalysis. This method deals with the oxidation mostly of organic molecules and compounds by means of solid metal oxide semiconductor as catalyst, which is activated by the incidence of radiation of an appropriate wavelength. It can take place both in the aqueous phase as well as in the gas phase. Among AOPs, heterogeneous photocatalysis appears as the most emerging destructive technology. Chemical treatment of wastewaters by AOPs can result in the complete mineralization of the pollutants to simple harmless end products such as carbon dioxide, water and inorganic salts. Ideally, a semiconductor photocatalyst for the purification of water should be chemically and biologically inert, photocatalitcally active, easy to produce and use, and activated by UV or sunlight [8].

$\mathrm{TiO}_{2}$ photocatalysis has been known to mineralize and decontaminate dyes because of its high surface activity and desirable physical as well as chemical properties [9]. $\mathrm{TiO}_{2}$ possesses a band gap of $3.4 \mathrm{eV}$ comparable to the wavelength of UV light and the photocatalytic activity of $\mathrm{TiO}_{2}$ is dependent particularly on its structural properties, crystal effects, particle size distribution, porosity, band gap and surface hydroxyl density [10]. Titanium dioxide $\left(\mathrm{TiO}_{2}\right)$, due to its non-toxic, inexpensive, and high reactive nature has been extensively investigated as a heterogeneous photocatalyst for the remediation of contaminated environment [11]. One of the alternative techniques to enhance the photocatalytic performance has been coupling of these large band gap semiconductors with small band gap conducting polymers. Although, wide band materials cannot absorb visible light, they can be "sensitized" by the narrow band gap semiconductor materials to enable the newly form composite system to absorb light in the visible region due to the strong coupling effect [12]. Conducting polymers is a prospective class of new materials that combine solubility, processability, and flexibility of plastics with electrical and optical properties of metals and semiconductors. Typical CPs includes polyacetylene (PA), polyaniline (PANI), polypyrrole (PPy), polythiophene (PT), polyfuran (PF), etc.

\section{Literature Review}

\subsection{Basic Concepts -Nanotechnology and Nanomaterials}

In general, nanotechnology can be understood as a technology of design, fabrication and applications of nanostructures and nanomaterials, as well as fundamental understanding of physical properties and phenomena of nanomaterials and nanostructures. Nanomaterials, compared to bulk materials, have the scales ranging from individual atoms or molecules to submicron dimensions at least in one dimension. Nanomaterials and nanotechnology have found the significant applications in physical, chemical and biological systems. Nanostructured materials can be made with unique nanostructures and properties. This field is expected to open new venues in science and technology $[13,14]$.

\subsection{Heterojunction Photocatalysts and Heterojunctions}

Heterojunction is defined as the interface between two different semiconductors with unequal band structure. Typically, there are three types of conventional semiconductor heterojunctions; namely (i) straddling type (ii) staggered type, and (iii) those with a broken gap. In type-I (straddling type heterojunctions), the energy band gap of semiconductor $\mathrm{A}$ is wider than $\mathrm{B}$, (as shown in Figure 1), resulting in the accumulation of the charge carriers on the semiconductor with smaller band gap. Since both electron and hole are accumulated on the same semiconductor, the recombination of charge carriers is still possible. In type-II (staggered type) heterojunction, the valence and CBs of semiconductor A are higher and lower than those of B. This results in the spatial separation of charge carriers which prevents the recombination of electrons and holes. The typeIII heterojunction (with broken gap) is the same as the staggered type except that the staggered gap becomes so wide that electron-hole migration is not possible, therefore, the separation cannot occur [15].

Besides conventional heterojunction, many other forms of heterojunctions have also been studied. These include $p-n$ heterojunction, surface heterojunction, direct Z-scheme heterojunction and semiconductor/graphene heterojunction. A p-n junction improves the photocatalytic performance by providing an additional electric field. This is achieved by combining n-type and p-type semiconductors. On the other hand, a surface heterojunction involves creating different crystal facets on the exposed surface of a semiconductor [16, 17]. Although these heterojunctions tend to enhance the electron-hole separation, they also reduce the redox ability of the photocatalyst. In order to overcome this problem, Zscheme heterojunction has been employed to maximize the redox potential of the heterojunction systems. Z-scheme photocatalytic system consists of two different semiconductors, 
and an acceptor/donor pair. The two semiconductors are not in a physical contact, instead the migration of the photogenerated

holes takes place through the acceptor/donor pair [18].
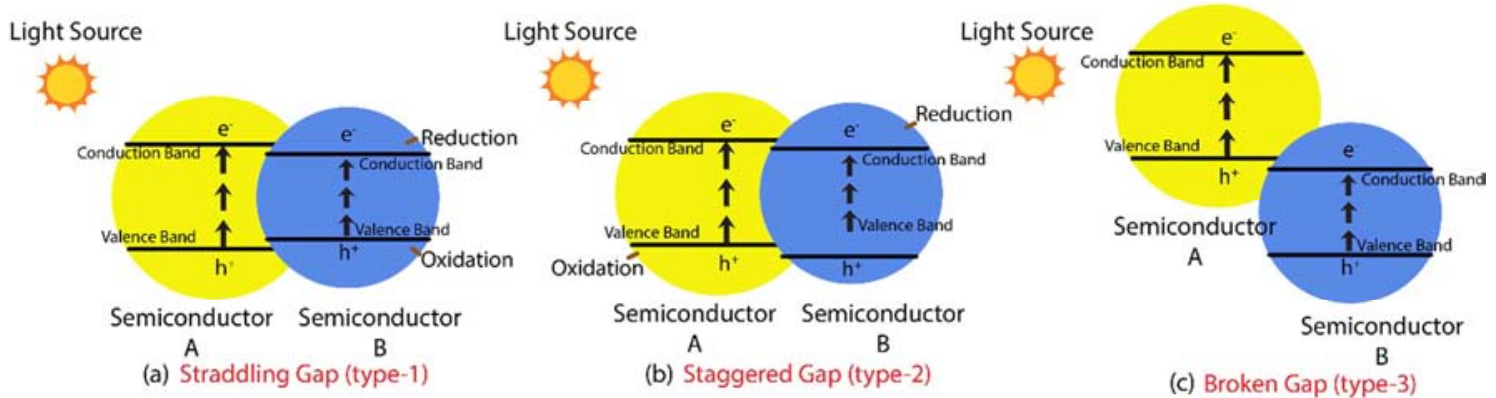

Figure 1. Types of heterojunction (a) straddling gap, (b) staggered gap, (c) broken Gap.

\subsection{Photocatalytic Reactor Design}

A photocatalytic reactor for water or wastewater treatment can be as simple as the one shown in Figure 2, which consists of photocatalyst coated glass and a UV lamp in the center [19]. However, in order to increase the irradiated surface area and to improve the efficiency, the photocatalytic reactors have been modified in many ways in the recent years.

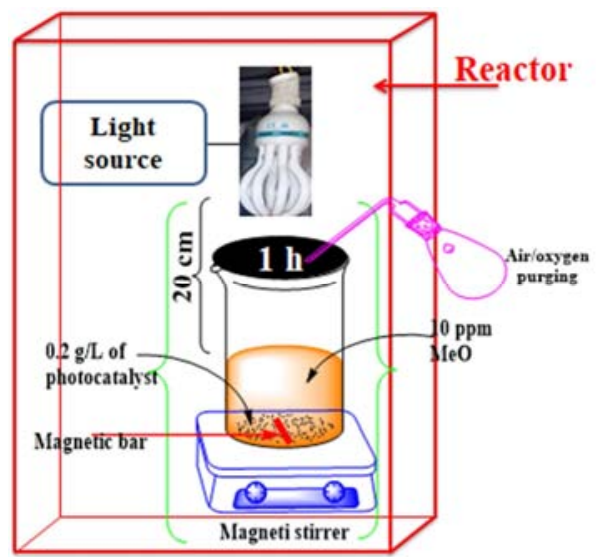

Figure 2. (a) A simple photocatalytic reactor which consists of nanocomposite coated glass beads and a UV lamp in the center.

In this study, the irradiance in the annulus of the reactor was measured to be $60 \mathrm{Wm}^{-2}$. The performance of the reactor was evaluated using Methyl orange as a model pollutant and industrial waste water influent. The initial concentration of the pollutants was $10 \mathrm{ppm}$ and the experiments were done with a catalyst dose of $0.2 \mathrm{~g} / \mathrm{L}$. Synthetic air was fed into the reactor and a constant agitation of the test solution was provided by a magnetic stirrer. Due to the complexity of the wastewater which includes not only mixture of organic dyes but also other chemicals from the bleaching steps, the degradation efficiency in the real wastewater sample was found to be lower than that of model MeO solution [19].

\subsection{Reaction Mechanism of Photocatalytic Degradation}

In general, the photocatalytic degradation involves several steps such as adsorption-desorption, electron-hole pair production, recombination of electron pair and chemical reaction [20]. The general mechanism of photocatalytic degradation of organic molecules is explained in the Figure bellow [21]. When the photocatalyst is irradiated with photons of energy equal to or more than band gap energy of it, the electrons (e-) are excited from the valence band (VB) to the conduction band (CB) with the simultaneous creation of holes $\left(\mathrm{h}^{+}\right)$in the VB:

$$
\text { Photocatalyst }+\mathrm{hv} \rightarrow \mathrm{e}_{\mathrm{CB}}{ }^{-}+\mathrm{h}_{\mathrm{VB}}{ }^{+}
$$

Where; hv is the energy essential to transfer the electron from valence band (VB) to conduction band (CB). The photocatalytic reaction is initiated when photogenerated electrons are transferred from the filled $\mathrm{VB}$ of the metal oxide to the empty $\mathrm{CB}$, leaving positive holes in the VB. The photogenerated electron then migrates to the metal oxide surface where separation and redox reaction occur. Both reduction and oxidation processes can occur on the surface of the photoexcited metal oxide only if the process is thermodynamically feasible. The photoinduced holes at the VB then react with the adsorbed water molecules to produce $\mathrm{OH} \bullet$ radical:

$$
\mathrm{H}_{2} \mathrm{O}+\mathrm{h}_{\mathrm{VB}}^{+} \rightarrow \mathrm{HO} \bullet+\mathrm{H}^{+}
$$

Instantaneously, electrons in the $\mathrm{CB}$ also react with the adsorbed oxygen $\left(\mathrm{O}_{2}\right)$ molecule on the photocatalyst surface to produce superoxide radicals $\left(\mathrm{O}_{2}{ }^{--}\right)$:

$$
\mathrm{e}_{\mathrm{CB}}{ }^{-}+\mathrm{O}_{2} \rightarrow \mathrm{O}_{2}{ }^{--}
$$

Consequently, $\mathrm{O}_{2}{ }^{--}$could react with $\mathrm{H}_{2} \mathrm{O}$ to produce hydroperoxy radical $\left(\mathrm{HO}_{2}{ }^{\circ}\right)$ and hydroxyl radical $\left({ }^{\circ} \mathrm{OH}\right)$, which are strong oxidizing agents to decompose the organic molecule:

$$
\mathrm{O}_{2}^{\cdot-}+\mathrm{H}_{2} \mathrm{O} \rightarrow \mathrm{HO}_{2}^{\cdot}+{ }^{\cdot} \mathrm{OH}
$$

Simultaneously, the photoinduced holes could be trapped by surface hydroxyl groups $\left(\right.$ or $\mathrm{H}_{2} \mathrm{O}$ ) on the photocatalyst surface to give hydroxyl radicals $\left(\mathrm{OH}^{\circ}\right)$ :

$$
\mathrm{h}_{\mathrm{VB}}{ }^{+}+\mathrm{H}_{2} \mathrm{O} \rightarrow \cdot \mathrm{OH}+\mathrm{H}^{+}
$$

The $\mathrm{HO} \bullet$ and $\mathrm{O}_{2}{ }^{--}$radicals formed are extremely powerful oxidizing and reducing agent to attack the adsorbed pollutants, causing them to mineralize depending on their stability level and structure. 


$$
\begin{gathered}
\cdot \mathrm{OH} / \mathrm{O}_{2}{ }^{-}+\text {organic molecules }(\mathrm{MeO})+\mathrm{O}_{2} \\
\rightarrow \text { Products }\left(\mathrm{CO}_{2} \text { and } \mathrm{H}_{2} \mathrm{O}\right)
\end{gathered}
$$

Meanwhile, recombination of positive hole and electron could take place which could reduce the photocatalytic activity of prepared nanocatalyst:

$$
\mathrm{e}_{\mathrm{CB}}{ }^{-}+\mathrm{h}_{\mathrm{VB}}{ }^{+} \rightarrow \mathrm{PC}+\text { heat }
$$

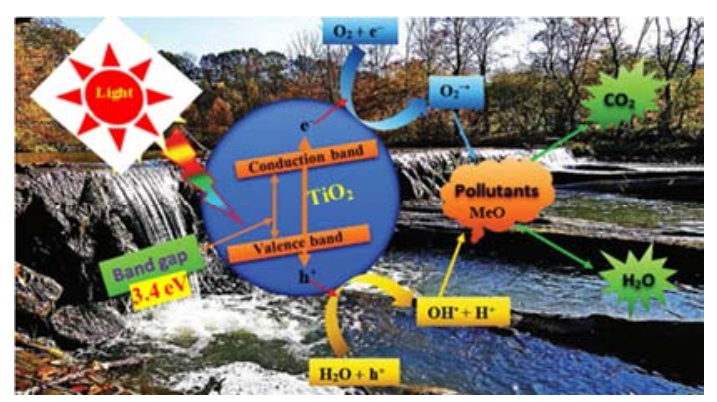

Figure 1. Schematic diagram of photocatalytic degradation of organic effluent.

\subsection{Preparation Methods of Nanocatalyst}

\subsubsection{Sol-gel Method}

Sol-gel method gained attention as a promising method for the synthesis of nanomaterials owing to their mild reaction conditions and building up the materials from molecular precursors leading to variation in materials and properties. The sol-gel process involves inorganic precursors that undergo various chemical reactions, resulting in the formation of a three-dimensional molecular network. Catalyst starting material is dissolved in the suitable solvent and then precipitating agent is added dropwise with vigorous stirring and solvent and precipitate (gel) are separated [22].

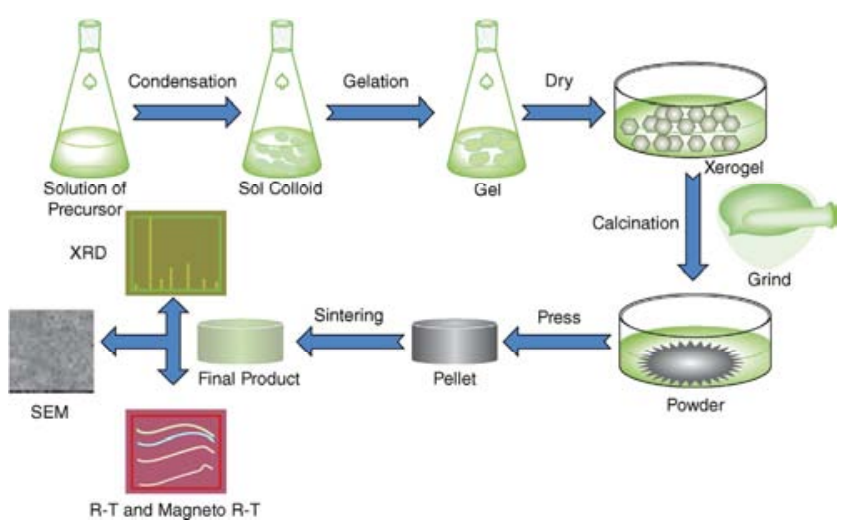

Figure 2. Schematic representation of sol-gel process of synthesis of nanomaterials.

\subsubsection{Impregnation Method}

In impregnation techniques, the support is contacted with a precursor solution, in other word impregnation is related to ion exchange (adsorption processes) and the interaction with the support is dominant. Thus, low loadings, often for precious metals, are achieved by adsorption of the precursor molecules onto surface groups of the support (ion adsorption) or through the exchange of ions in, after which excess precursor are removed. When higher loadings are required, the washing step is skipped and the support is directly dried, so that all precursor ends up on the support. Impregnation can be performed to incipient wetness, whereby the pores of the support are filled with precursor solution, to prevent deposition on the external surface of the catalyst grains and to limit waste [23].
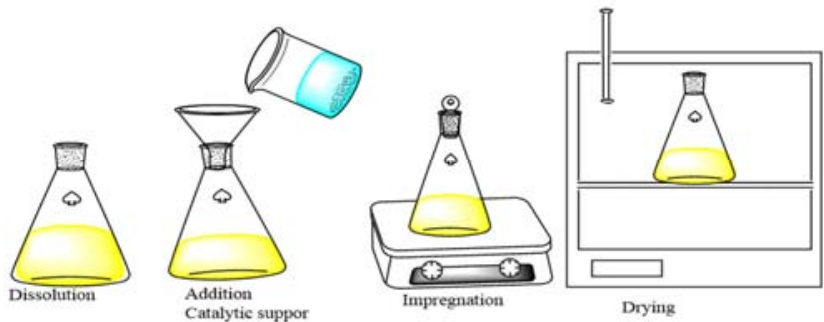

Figure 5. Schematic representation of impregnation process of synthesis of nanomaterials.

\subsubsection{Co-precipitation Method}

Synthesis of photonanocatalyst by co-precipitation method is like the figure given bellow [6]. Inorganic salts are used as precursors, dissolved in water and other solvents to obtain homogenous solution of ions, and then these salts start precipitating as hydroxides or oxalates when the critical concentration of species is attained followed by nucleation and growth phases. After precipitation, filtration and washing is done followed by calcination to convert hydroxide into oxides with a definite crystalline structure. The precipitating medium usually employed includes $\mathrm{NaOH}, \mathrm{NH}_{3}$ or $\mathrm{NH}_{4} \mathrm{OH}$, $\mathrm{Na}_{2} \mathrm{CO}_{3}$ etc. The method offers the advantage of being low cost, simple, water based reaction, flexibility, mild reaction conditions and size control.

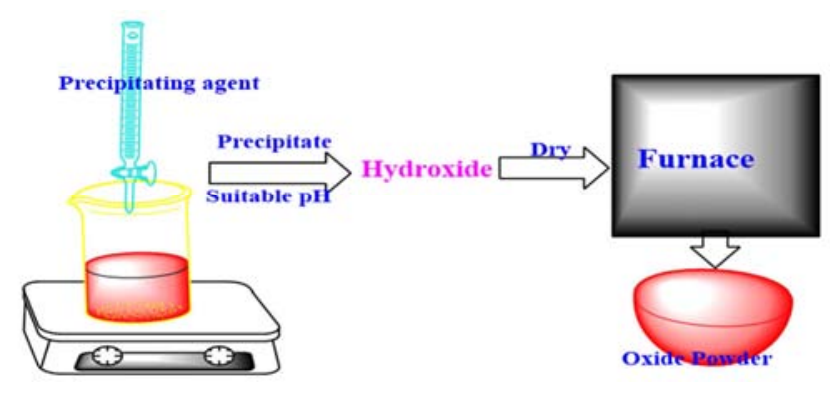

Figure 6. Synthesis of photonanocatalyst by co-precipitation method.

\subsubsection{Hydrothermal Method}

Hydrothermal synthesis is widely used for the preparation of metal oxide nanoparticles which can easily be obtained through hydrothermal treatment of peptized precipitates of a metal precursor with water. This method can be useful to control grain size, particle morphology, crystalline phase and surface chemistry through regulation of the solution composition, reaction temperature, pressure, solvent properties, additives and aging time [24]. 


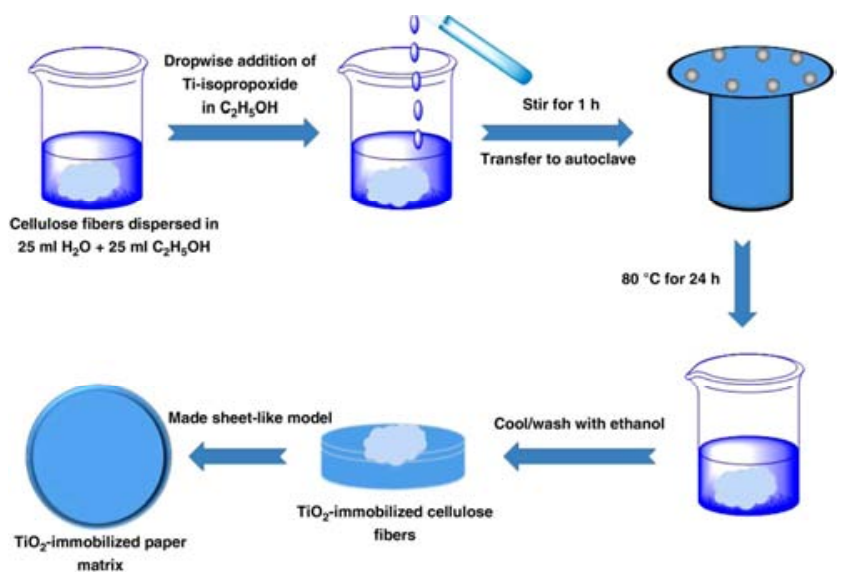

Figure 7. Synthesis of $\mathrm{TiO}_{2}$ based photocatalyst by hydrothermal treatment method.

\subsection{Characterization Methods}

\subsubsection{Powder X-ray Diffraction (XRD)}

$\mathrm{XRD}$ is used to assess the crystallinity of synthesized nanoparticles [25]. This technique is employed to identify and quantitatively examine various crystalline forms or the elemental composition of natural and manufactured materials or nanoparticles. To accomplish this, the structure and lattice parameters of the diffracted powder specimen are analyzed by measuring the angle of diffraction, when X-ray beam are made to incident on them. A beam of X-rays of wavelength $\lambda$ is directed to the crystal at an angle $\theta$ to the atomic planes. The atomic planes are considered to be semitransparent, that is, they allow a part of the X-ray to pass through and reflect the other part, the incident angle $\theta$ being equal to the reflected angle (called Bragg angle). Particle size is determined based on the width of the X-ray peaks using the Debye-Scherrer formula [26].

$$
\mathrm{D}=\frac{\mathrm{k} \lambda}{\mathrm{B} \cos \theta}
$$

Where, $\mathrm{D}=$ crystallite size in $\mathrm{nm}, \mathrm{K}=$ the shape factor constant and taken as $0.9 ; \beta$ is the full width at half maximum (FWHM) in radians, $\lambda$ is the wave length of the X-ray $(0.15406 \mathrm{~nm})$ for $\mathrm{Cu}$ target $\mathrm{K} \alpha 1$ radiation and $\theta$ is the Bragg's angle.

\subsubsection{Scanning Electron Microscopy (SEM)}

SEM is a widely accepted technique to extract structural and chemical information point-by-point from a region of interest in the sample. It is generally employed to examine the surface morphologies of the material at higher magnifications. In addition, if an energy dispersive X-ray (EDX) spectroscopy analysis system is attached to the scanning electron microscope, both qualitative and quantitative chemical analysis can be carried out [27].

\subsubsection{UV-Visible Diffuse Reflectance Spectroscopy (UV-Vis)}

The optical absorption plays an important role in the photocatalysis, especially in the visible-light photodegradation of contaminants. The wavelength at the absorption edge for a semiconductor is determined as the intercept on the wavelength axis for a tangential line drawn on the absorption spectrum [28]. Diffuse reflectance spectroscopy is a sensitive technique which uses the interaction of light, absorption and scattering to produce characteristic spectrum providing information regarding the structure and composition of the material. Electronic transition in materials can be observed in liquid state using UV-Visible spectroscopy. But in the case of insoluble solids, UV-Visible diffuse reflectance is used. It is used to study the electronic transitions between bands in the case of atoms, ions and molecules in gas, liquid or solid state. This technique is performed on the basis of electronic excitation by the absorption of light [29].

\subsubsection{Fourier Transforms Infrared Spectroscopy (FTIR)}

FTIR spectroscopy is conducted to identify the functional groups present on nanoparticles [26]. The spectrum represents a fingerprint of the nanoparticles consisting of absorption peaks that correspond to the frequencies of vibrations between the bonds of atoms in the nanoparticle. Since each type of nanoparticle contains a unique combination of atoms, we can identify functional groups present inside the nanoparticles based on the FTIR spectra. The number of functional groups present in the nanomaterial can be determined by the size of the peaks of the spectrum. The transmission spectra for the nanoparticles are obtained by the formation of thin, transparent potassium bromide $(\mathrm{KBr})$ pellets containing the compound of interest. The transmission spectra are obtained after purging in dry air and background corrected relative to a reference blank sample $(\mathrm{KBr})$. Commonly, the vibrational spectroscopy covers a wavenumber ranging from $4000-400 \mathrm{~cm}^{-1}$ which is used to excite stretching and bending molecular vibrations [30].

\subsubsection{Photoluminescence Spectroscopy (PL)}

Luminescence refers to the emission of light by a material through any process other than blackbody radiation. PL is a contactless, nondestructive method of probing the electronic structure of materials [31]. In PL the physical and chemical properties of materials are measured by using photons to induce excited electronic states in the material system and analyzing the optical emission as these states relax. It is a process in which a chemical compound absorbs photons (electromagnetic radiation), thus jumping to a higher electronic energy state, and then radiates photons, returning to a lower energy state. Photo-excitation causes electrons within the material to move into permissible excited states. When these electrons return to their equilibrium states, the excess energy is released and may include the emission of light, or luminescence. PL is mainly used as a diagnostic and development tool in semiconductor research, since it can provide information about the electronic structure and the emission mechanism of the material [32].

\subsection{Application of $\mathrm{TiO}_{2}$-Based Conducting Polymers in Photocatalysis}

Conducting polymers contain an extended $\pi$-electron 
system which imparts them high stability as well as a high mobility charge carriers that are well suited for acting as sensitizers for wide bandgap semiconductors [33, 34]. Conducting polymers generally behaves as p-type semiconductor and thus $\mathrm{p}$-n junctions can be tailored by combining a p-type conducting polymer with an n-type semiconductor which can overcome the drawbacks of the latter, such as its poor response to visible light, high rate of electron-hole recombination, leaching, and thermal decomposition. Because of their semiconductor energy level structure, broad absorption spectra and very high stability under irradiation of solar light, CPs can be used to photosensitize semiconductor oxides and to obtain the novel photocatalysts response to the visible light [35].

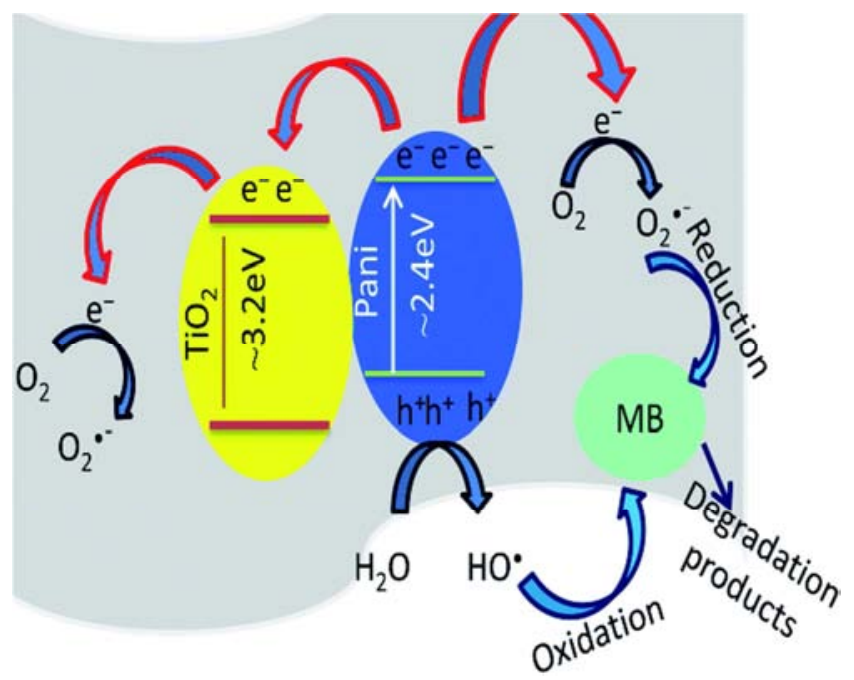

Figure 8. Mechanism of photodegradation of organic contaminants by polyaniline supported $\mathrm{TiO}_{2}$ photocatalyst under visible light irradiation and under UV light irradiation.

\subsubsection{Polyaniline/TiO ${ }_{2}$-Based Photocatalysts and Mechanisms}

When the polymer, PANI, absorbs visible light irradiation, $\pi-\pi^{*}$ transition is induced which transfers the photogenerated electrons to the $\pi^{*}$ orbital of PANI. Since this $\pi^{*}$ orbital matches well in energy level and has chemical bond interaction with the d-orbital i.e. conduction band (CB) of Titania. The excited electrons can efficiently migrate from PANI to $\mathrm{TiO}_{2}$. Subsequently, these photogenerated electrons can be transferred to the surface of the photocatalyst to react with water and oxygen to yield powerful hydroxyl and superoxide anion radicals leading to oxidation of the adsorbed organic contaminants. Similarly, under UV light irradiation, the photogenerated holes in the valence band (VB) of $\mathrm{TiO}_{2}$ can transfer directly to the HOMO (highest occupied molecular orbital) of PANI. This becomes possible because the energy level of HOMO in PANI is between VB and CB of Titania and the VB of $\mathrm{TiO}_{2}$ matches well with $\mathrm{HOMO}$ of PANI. These photogenerated holes can easily emigrate to the surface of the photocatalyst and subsequently oxidize the adsorbed organic pollutants directly. In short, under both UV and Vis light illumination, the synergic effect of PANI causes rapid charge separation, slow charge recombination and thus an enhanced PCA of the prepared $\mathrm{TiO}_{2} / \mathrm{PANI}$ photocatalysts.

Liao and his coworker compare the photocatalytic capability of $\mathrm{M}-\mathrm{TiO}_{2}$ and $\mathrm{PANI} / \mathrm{M}-\mathrm{TiO}_{2}$ with different mass ratios under visible light illumination $(>400 \mathrm{~nm})$ was evaluated by comparing the photodegradation efficiency of $\mathrm{RhB}$ as presented in Figure 9 [36]. During $30 \mathrm{~min}$ illumination, only $10 \%$ of the $\mathrm{RhB}$ was photodegraded by $\mathrm{M}$ $\mathrm{TiO}_{2}$ under visible light irradiation because of the limitation of wide band gap. While after modified with PANI, the photocatalytic capability of $\mathrm{PANI} / \mathrm{M}-\mathrm{TiO}_{2}$ samples enhanced gradually with increasing the proportion of PANI. The optimal photocatalytic capability was achieved when the proportion of PANI reached $6 \%$ with the photodegradation efficiency being $99.8 \%$. But while the proportion of PANI exceeded $6 \%$, the photocatalytic capability of PANI/M-TiO samples decreased and $91.7 \%$ of $\mathrm{RhB}$ was photodegraded with $9 \% \mathrm{PANI} / \mathrm{M}-\mathrm{TiO}_{2}$. This was because when the ratio of PANI surpassed $6 \%$, the superfluous PANI molecules tended to aggregate on the surface of $\mathrm{TiO}_{2}$, which affected the transfer of the photoinduced carriers and separation of electron-holes pairs [37]. As shown in Figure 9e, 50.1\% of $\mathrm{RhB}$ was photodegraded by $\mathrm{PANI} / \mathrm{NP}-\mathrm{TiO}_{2}$ in $30 \mathrm{~min}$, which was only half of that with $6 \% \mathrm{PANI} / \mathrm{M}-\mathrm{TiO}_{2}$. Under the same experimental conditions, the kinetic constant of $\mathrm{RhB}$ photodegradation with $6 \% \mathrm{PANI} / \mathrm{M}-\mathrm{TiO}_{2}$ was 5.04 times as great as that of the $\mathrm{PANI} / \mathrm{NP}-\mathrm{TiO}_{2}$, which showed the advantage of the unique structure in the $\mathrm{PANI} / \mathrm{M}-\mathrm{TiO}_{2}$ photocatalyst for efficient photocatalysis.

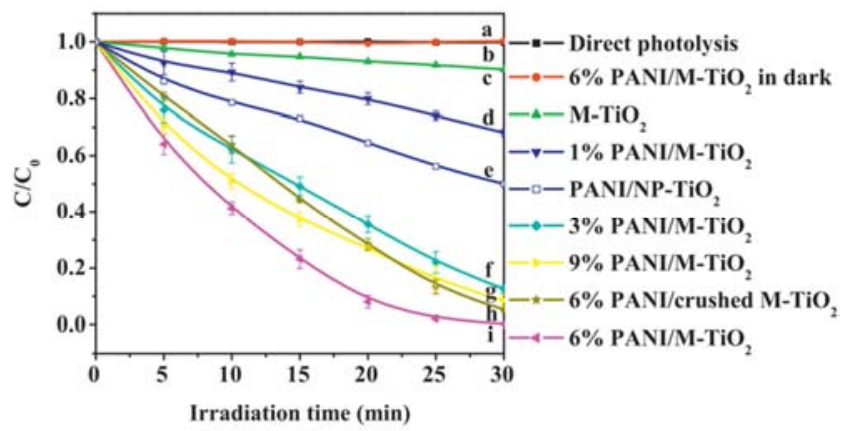

Figure 9. Process of photocatalytic degradation of $R h B$ under visible light irradiation (> $400 \mathrm{~nm}, C_{0}=10 \mathrm{mg} / \mathrm{L}, I_{0}=100 \mathrm{~mW}^{2} \mathrm{~cm}^{2}$ ).

\subsubsection{Polypyrrole/TiO ${ }_{2}$ Photocatalysts}

Polypyrrole is also among the most extensively investigated conducting polymers due to its high conductivity, electrochemical reversibility, and the ease of preparation through chemical or electrochemical routes. PPy is known to be chemically and thermally stable and undergoes only slow degradation in ambient atmosphere. Hence, it has also been used as a stable photosensitizer to improve the photocatalysis of $\mathrm{TiO}_{2}$ under visible light [37].

Sangareswari and Sundaram estimated the photocatalytic activity of $\mathrm{PPy}-\mathrm{TiO}_{2}$ nanocomposites by measuring the decolorization rates of methyl blue (MB) [38]. In the experiments, $50 \mathrm{~mL}$ of $\mathrm{MB}$ and $20 \mathrm{mg}$ of catalysts were kept under dark room to get adsorption desorption equilibrium. 
The MB dye was effectively degraded by $\mathrm{PPy}_{-} \mathrm{TiO}_{2}$ nanocomposite under solar light irradiation. The fraction removal of dye degradation was higher $(93 \%)$ in $\mathrm{PPy}_{-} \mathrm{TiO}_{2}$ nanocomposite than $\mathrm{TiO}_{2}$ as shown in Figure 10.

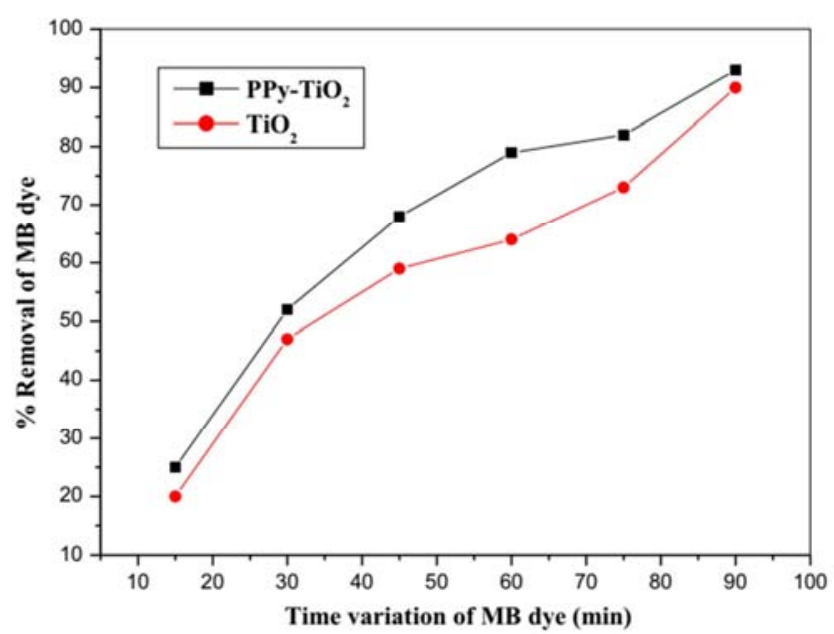

Figure 10. The photodegradation of $\mathrm{MB}$ dye on $\mathrm{PPy}^{-\mathrm{Ti} \mathrm{O}_{2}}$ nanocomposite and $\mathrm{TiO}_{2}$.

\subsubsection{Polythiophene/TiO ${ }_{2}$ Photocatalysts}

Conducting polymers, such as PTh in the place of dyes, is an efficient method of resolving these problems because the polymer can be coated on the surface of metal oxides, and the resulting composite would exhibit strong interactions as well as high absorption in the UV and visible region of the solar spectrum [37].

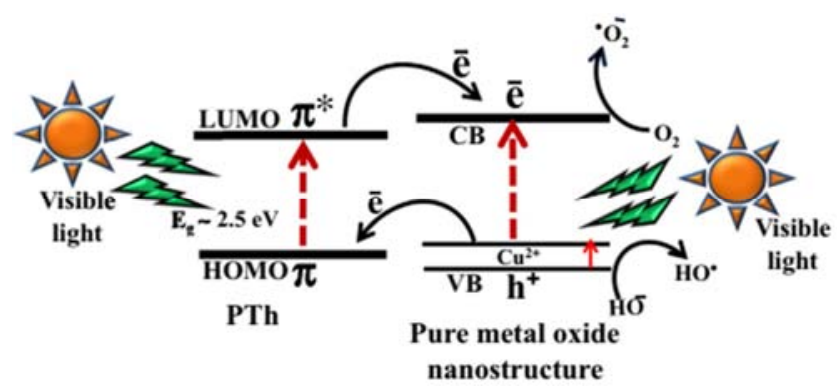

Figure 11. Metal mediated electron transfer to PTh and metal oxide.

$\mathrm{Xu}$ and co-workers also prepared $\mathrm{PT} / \mathrm{TiO}_{2}$ composites by photoinduced polymerization of thiophene and studied its catalytic behavior towards the degradation of $\mathrm{RhB}$ [39]. The particle size of the $\mathrm{TiO}_{2}$ composites was $20-30 \mathrm{~nm}$ while that of $\mathrm{PT} / \mathrm{TiO}_{2}$ composites was also 20-30 nm. After $180 \mathrm{~min}$ exposure towards UV irradiation, $\mathrm{RhB}$ percent degradation in the presence of the $\mathrm{PT} / \mathrm{TiO}_{2}$ composites was almost $75.6 \%$, while the degradation ratio of $\mathrm{RhB}$ after $10 \mathrm{~h}$ of visible light exposure using $\mathrm{PT} / \mathrm{TiO}_{2}$ composites was $98 \%$.
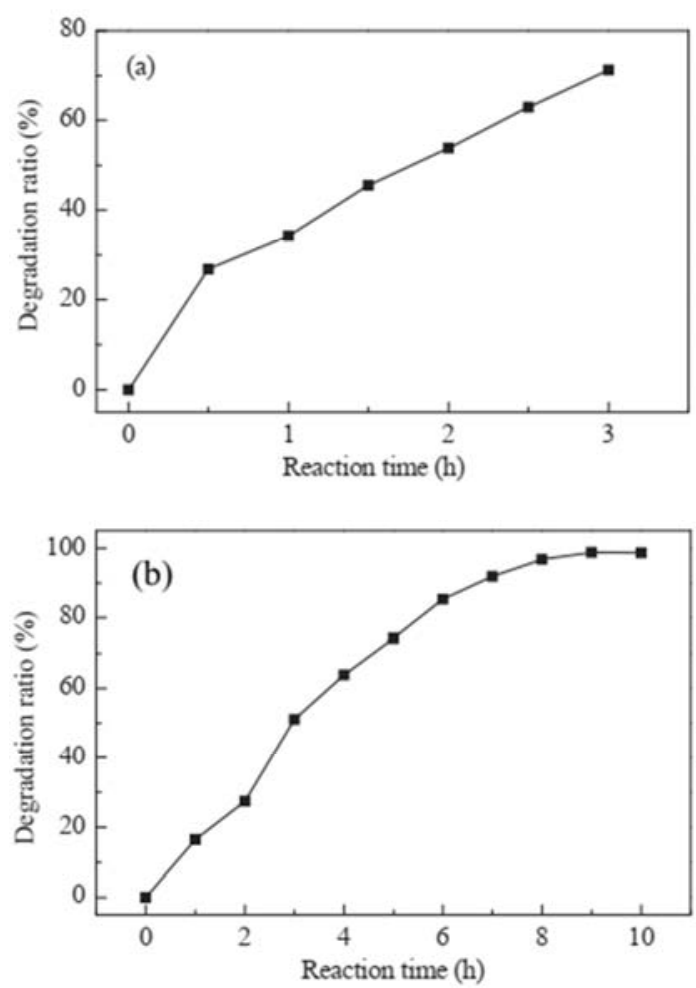

Figure 12. Variation in the degradation ratio of the RhB solution with experimental time under (a) UV irradiation (b) visible light irradiation.

\subsection{Other Supports in $\mathrm{TiO}_{2}$ Photocatalysts}

\subsubsection{Doping}

Doping of $\mathrm{TiO}_{2}$ with various metallic species is one possible solving route to prevent the recombination of charge carriers. The metal nanoparticles on the surface of $\mathrm{TiO}_{2}$ will act as an electron reservoir to trap electrons which can greatly increase the efficiency of charge separation, resulting in the improvement of $\mathrm{TiO}_{2}$ photocatalytic activity. Furthermore, the addition of dopants can change the surface properties of $\mathrm{TiO}_{2}$ catalyst such as surface area and surface acidity [40]. Some reports on the doping of $\mathrm{TiO}_{2}$ nanoparticles will be reviewed here: [41] prepared doped anatase-structure $\mathrm{TiO}_{2}$ nanoparticles $\left(\mathrm{Sb} / \mathrm{TiO}_{2}, \mathrm{Nb} / \mathrm{TiO}_{2}\right.$, $\mathrm{Fe} / \mathrm{TiO}_{2}$, and $\mathrm{Co} / \mathrm{TiO}_{2}$ ) by means of a hydrothermal methodology preceded by a precipitation doping step.

Murcia and co-workers in their work found the evolution of methylene blue concentration during the photodegradation of this dye over $\mathrm{S}-\mathrm{TiO}_{2}$ and $\mathrm{M}-\mathrm{TiO}_{2}$ photocatalysts $(\mathrm{M}=\mathrm{Au}$ or Pt) [42]. As it can be seen, dye concentration progressively decreases with the photoreaction time. The lowest MB degradation was observed by using bare $\mathrm{TiO}_{2}$ as photocatalyst. The highest degradation rate was achieved over the $\mathrm{Au}-\mathrm{S}-\mathrm{TiO}_{2}$ photocatalyst prepared at $120 \mathrm{~min}$ of deposition time. In the case of the platinized catalysts (Pt-S$\mathrm{TiO}_{2}$ ) the photocatalytic activity was higher with the catalyst prepared at 120 min of deposition time than the catalysts Pt$\mathrm{S}-\mathrm{TiO}_{2}$ prepared at $15 \mathrm{~min}$ of deposition time. As it can be also seen in Figure 13, the activity of this last sample is even lower than the unmetallized $\mathrm{TiO}_{2}\left(\mathrm{~S}-\mathrm{TiO}_{2}\right)$. 

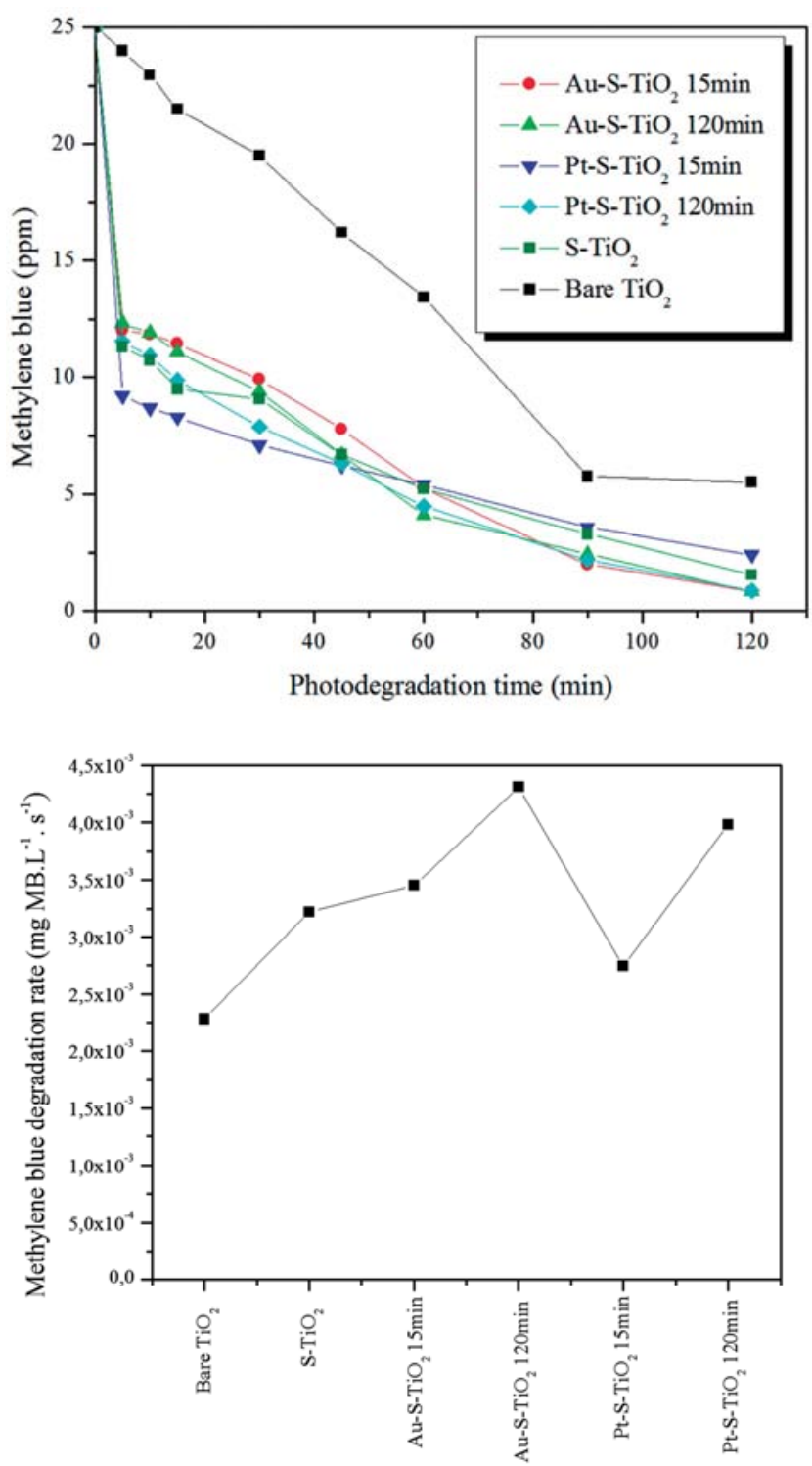

Figure 13. Evolution of the dye concentration during $M B$ photodegradation over unmetallized and metallized $\mathrm{TiO}_{2}$ photocatalysts prepared at 15 and 120 min of deposition time.

\subsubsection{Coupling}

It is possible to create coupled colloidal structures, in which illumination of one semiconductor produces a response in the other semiconductor at the interface between them [43]. Coupled semiconductor photocatalysts exhibit very high photocatalytic activity for both gas and liquid phase reactions by increasing the charge separation and extending the energy range of photoexcitation. The geometry of particles, surface texture, and particle size play a significant role in interparticle electron transfer. $\mathrm{TiO}_{2}$ coupling with other metal oxides is another approach in order to increase the lifetime of the photo-produced electron-hole pairs and improve the photocatalytic activity of $\mathrm{TiO}_{2}$. Recently, many studies related to $\mathrm{TiO}_{2}$ coupled with other metal oxides, such as $\mathrm{ZnO} / \mathrm{TiO}_{2}, \mathrm{Ag}_{3} \mathrm{PO}_{4} / \mathrm{TiO}_{2}, \mathrm{Cu}_{2} \mathrm{O} / \mathrm{TiO}_{2}$ and $\mathrm{CeO}_{2} / \mathrm{TiO}_{2}$, have been reported $[44,45]$.

Eskadnarloo and co-workers prepared $\mathrm{TiO}_{2} / \mathrm{CeO}_{2}$ coupled nanoparticles and used them in the photocatalytic removal of phenazopyridine under UV light irradiation [46]. A comparison of single and coupled photocatalysts for photocatalytic removal of the phenazopyridine has been performed. The results showed that the highest removal efficiency (66.64\%) was obtained using $\mathrm{TiO}_{2} / \mathrm{CeO}_{2}$ coupled nanoparticles, whereas at the same time, using $\mathrm{TiO}_{2}$ and $\mathrm{CeO}_{2}$ samples lead to $55.63 \%$ and $19.1 \%$ removal efficiency, respectively. They have suggested that the coupling $\mathrm{TiO}_{2}$ with $\mathrm{CeO}_{2}$ could produce special electrons and holes transfer from $\mathrm{TiO}_{2}$ to $\mathrm{CeO}_{2}$, which is able to facilitate the separation of the electron-hole pairs and thus improve the photocatalytic activity of the coupled photocatalyst. They justify their results by a simple mechanism representation of the coupled $\mathrm{CeO}_{2} / \mathrm{TiO}_{2}$ that is responsible for its UV light activity (Figure 14).

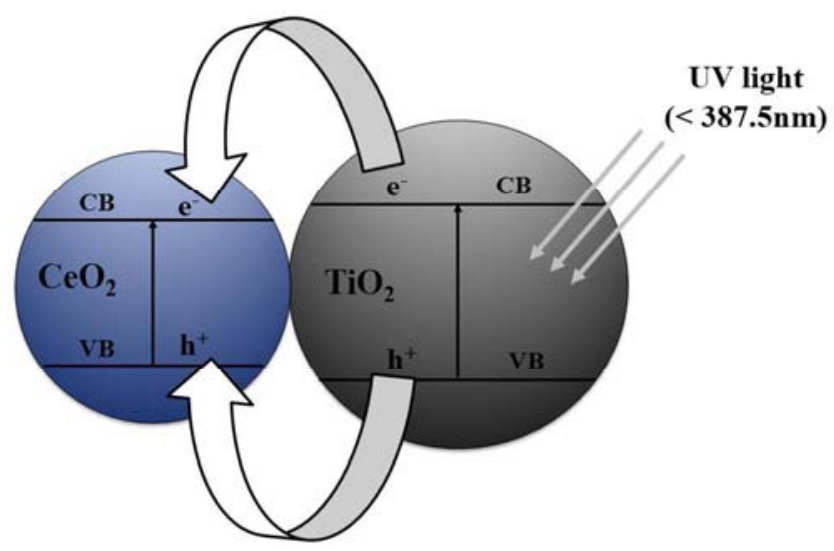

Figure 14. Possible photocatalytic mechanism of $\mathrm{TiO}_{2} / \mathrm{CeO}_{2}$ coupled nanoparticles under UV light irradiation.

\subsubsection{Mesoporous Clays}

$\mathrm{TiO}_{2}$ supported on inorganic clay minerals has received wide attention. The natural structure and adsorption ability of the clay materials can maintain large SSA, stability and consequently enhance the photocatalytic efficiency of the photocatalysts [47-49]. Therefore, the selection for the suitable clay minerals is the key step for the success in developing the immobilized-catalysts. Different types of clays have been investigated; bentonite [50], sepiolite [51], montmorillonite [52], zeolite [53] and kaolinite [54].

$\mathrm{Li}$ and co-workers reported that the photocatalytic performances of as-prepared photocatalysts were measured to degrade antibiotics under UV light irradiation [55]. Figure 15a shows the degradation curves of tetracycline hydrochloride using $\mathrm{FK}, \mathrm{RK}, \mathrm{FK} / \mathrm{TiO}_{2}, \mathrm{RK} / \mathrm{TiO}_{2}$ and bare $\mathrm{TiO}_{2}$ photocatalysts. The bare $\mathrm{TiO}_{2}, \mathrm{FK}$ and RK exhibit 9, 22 and $19 \%$ of tetracycline hydrochloride adsorption after 30 min dark adsorption equilibrium, respectively. Upon UV light irradiation, the tetracycline hydrochloride can be slightly degraded with bare $\mathrm{TiO}_{2}$, while there is no degradation by FK and RK. The photodegradation activity is enhanced by supporting $\mathrm{TiO}_{2}$ nanoparticles on the kaolinites, and $\mathrm{FK} / \mathrm{TiO}_{2}$ composites show the highest photodegradation activity. After irradiation for $60 \mathrm{~min}$, the photodegradation rate of $\mathrm{FK} / \mathrm{TiO}_{2}$ composite is $98 \%$, but only $84 \%$ for the $\mathrm{RK} / \mathrm{TiO}_{2}$. It is 
reported that photocatalytic decomposition of tetracycline hydrochloride follows the pseudo-first-order reaction kinetics [56]. As shown in Figure 15b, the rate constant for bare $\mathrm{TiO}_{2}$ is very small compared to that for clays $/ \mathrm{TiO}_{2}$ composites, and

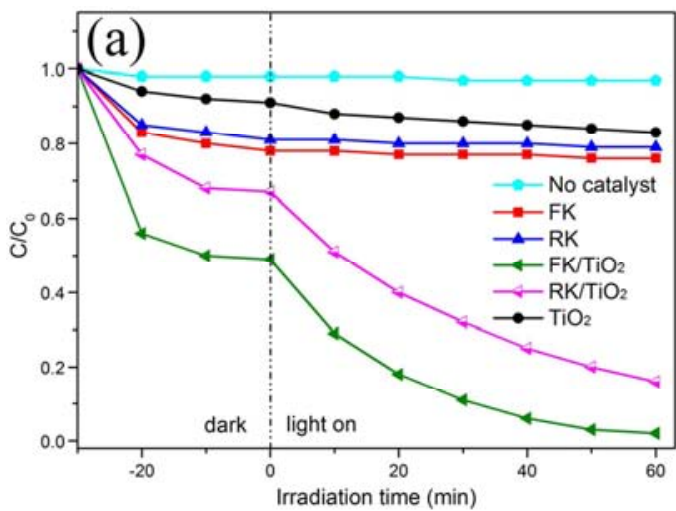

Figure 15. Photocatalytic properties and reaction mechanism of the samples. order plot with $\mathrm{FK} / \mathrm{TiO}_{2}, \mathrm{FK} / \mathrm{TiO}_{2}$ and bare $\mathrm{TiO}_{2}$ nanoparticles.

\subsection{Operational Parameters that Affect Photocatalytic Degradation}

\subsubsection{Effect of $\mathrm{pH}$}

$\mathrm{pH}$ influences the adsorption and dissociation of the organic molecule, surface charge of photocatalyst, and oxidation potential of the valence band. As the $\mathrm{pH}$ reduced, the functional groups are protonated, thus raising the positive charge of photocatalyst surface. The surface of photocatalyst will be charged negatively and results in the increased adsorption cationic molecules at higher $\mathrm{pH}$ value while in the reverse situation it would adsorb anionic molecules very easily. In the meantime, the increased $\mathrm{pH}$ value increases the hydroxyl radical generation [57]. But the degradation of organic molecules is repressed when the $\mathrm{pH}$ of solution is too high $(\mathrm{pH}>12)$, because hydroxyl ions compete with organic molecules for the adsorption on the surface of the catalysts. On the contrary, at low $\mathrm{pH}$, the adsorption of cationic organic molecule on the photocatalyst surface is reduced, because the surface of photocatalyst is positively charged which results in the decrease in adsorption of cationic organic molecules. Thus, the degradation efficiency is declined in lower $\mathrm{pH}$ or acidic solution [58].

Nasikhudin and co-workers investigated the photocatalytic activities of $\mathrm{TiO}_{2}$ nanoparticle in various condition (without $\mathrm{UV}$ and with UV light) and various $\mathrm{pH}$; acidic $\mathrm{pH}$ conditions $(\mathrm{pH}=4.1)$, neutral $(\mathrm{pH}=7)$, and base $(\mathrm{pH}=9,7)$. The results of the photocatalytic investigation degradation of methylene blue (MB) solution by $\mathrm{TiO}_{2}$ were shown in Figure 16 [59].

Figure 16 shows that a photocatalytic process that takes place under alkaline conditions will be faster than in neutral conditions. Otherwise the photocatalytic process that takes place in acidic conditions will be slower than in neutral conditions, this can be explained as follows. the rate constant of $\mathrm{FK} / \mathrm{TiO}_{2}$ is higher than that of $\mathrm{RK} / \mathrm{TiO}_{2}$. The enhanced photocatalytic activity for $\mathrm{FK} / \mathrm{TiO}_{2}$ composite can be attributed to the large surface area, decreased particle size and increasing density of active sites.

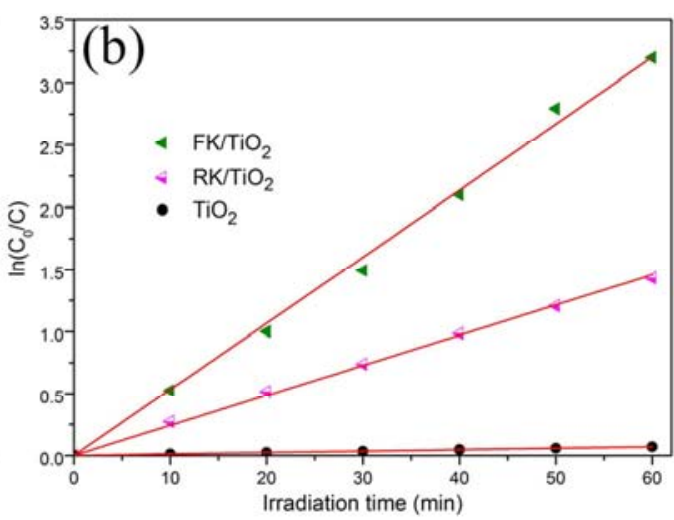

(a) Photocatalytic degradation curves of different samples, (b) pseudo-first-

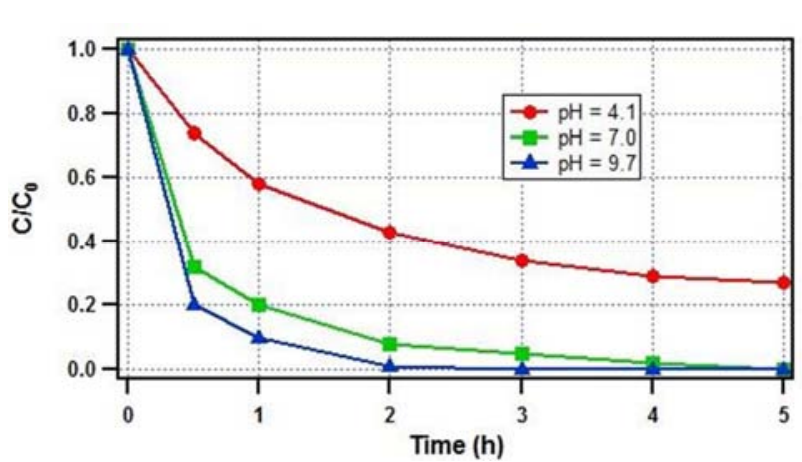

Figure 16. Photocatalytic activity of $\mathrm{TiO}_{2}$ nanoparticle in acid, neutral and alkaline condition.

In the neutral condition the hydroxyl radical $\left(\mathrm{HO}^{*}\right)$ is produced from the reaction

$$
\mathrm{h}_{\mathrm{vb}}{ }^{+}+\mathrm{H}_{2} \mathrm{O} \rightarrow \mathrm{H}^{+}+\mathrm{HO}^{*}
$$

Under alkaline conditions, the hydroxyl radical may also be produced directly from the $\left(\mathrm{HO}^{-}\right)$ion which interacts with the hole according to the following reaction

$$
\mathrm{h}_{\mathrm{vb}}{ }^{+}+\mathrm{OH}^{-} \rightarrow \mathrm{HO}^{*}
$$

Therefore under alkaline conditions, the resulting hydroxyl radical $\left(\mathrm{OH}^{*}\right)$ will be more numerous so that its photocatalytic ability will be better. In acidic conditions there exists an excess of $\mathrm{H}^{+}$, so that this excess $\mathrm{H}^{+}$will interact with the free electrons $\left(\mathrm{e}^{-}\right)$to form radicals $\left(\mathrm{H}^{*}\right)$. The formation of this radicals $\left(\mathrm{H}^{*}\right)$ will cause a backlash with $\mathrm{HO}^{*}$ and $\mathrm{H}^{*}$ return to $\mathrm{H}_{2} \mathrm{O}$.

$$
\mathrm{H}^{+}+\mathrm{e}^{-} \rightarrow \mathrm{H}^{*} \text { and } \mathrm{H}^{*}+\mathrm{HO}^{*} \rightarrow \mathrm{H}_{2} \mathrm{O}
$$

\subsubsection{Effect of Dye Concentration}

Increasing initial dye concentration reduces the photocatalyst degradation efficiency. It might be due to the increase of the initial concentration of organic compound in 
which more molecules were adsorbed on the surface of the photocatalyst. Also initial concentration of dye decreases the number of photons or path length of photon that is arrived on the surface of photocatalysis which reduces the excitation of electron from valance band to conduction band [60, 61].

Hadjltaief and co-workers studied the effect of dye concentration on the degradation of methyl green at varying concentrations between 25 and $150 \mathrm{mg} / \mathrm{L}$ with constant catalyst loading at $\mathrm{pH} 7$ [62]. The influence of initial dye concentration is shown in Figures 17 in the presence of $\mathrm{TiO}_{2}$ (P25) where a plot of $\ln \left(\mathrm{C} / \mathrm{C}_{0}\right)$ versus time of irradiation is represented. A linear relation between dye concentration and irradiation time has been observed. It was found that the increase in the dye concentration decreases the removal rate.

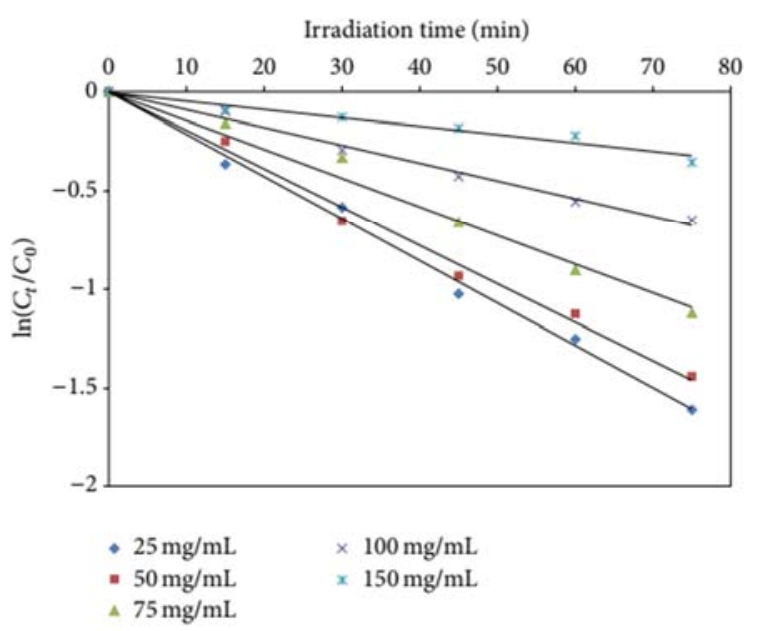

Figure 17. (a) Effect of initial dye concentration on photocatalytic degradation of $\mathrm{MG}$ using $\mathrm{TiO}_{2}$ (P25) (photocatalyst amount $=0.75 \mathrm{~g} / \mathrm{L}$ and irradiation time $=180$ min at $\mathrm{pH}=7$ ).

\subsubsection{Effect of Catalyst Loading}

In general, due to increasing in active sites, the rate of photocatalytic degradation of organic pollutants increases with photocatalyst dosage. This is mainly due to increase of hydroxyl radical produced from irradiated photocatalyst. Agglomeration of nanoparticles at high concentrations reasoning a decline in the number of surface active sites available for the photocatalytic degradation and deactivation of activated molecules could result from the collision of activated molecules with ground state molecules [63]. Concentration of $\mathrm{TiO}_{2}$ in the photocatalytic water treatment system affects the overall photocatalysis reaction rate in a true heterogeneous catalytic regime, where the amount of $\mathrm{TiO}_{2}$ is directly proportional to the overall photocatalytic reaction rate $[64,65]$.

Figure 18 shows the results of decomposition of $\mathrm{MB}$ obtained at different $\mathrm{TiO}_{2}$ particle dosages [66]. The microwave intensity was $0.4 \mathrm{~kW}$, and the DO concentration was $70 \mathrm{ppm}$. Addition of a larger amount of $\mathrm{TiO}_{2}$ particle resulted in a higher decomposition rate. Certain amount of MB was shown to be decomposed by MDEL and high concentration of DO without the aid of $\mathrm{TiO}_{2}$ photocatalytic reaction. The plots for the four cases were all fitted well by linear line, which indicates that decomposition of $\mathrm{MB}$ in the presence of $\mathrm{TiO}_{2}$ catalyst can be approximated by a pseudofirst-order reaction $\left(\frac{C}{C_{0}}=\exp (-\mathrm{Kt})\right)$.

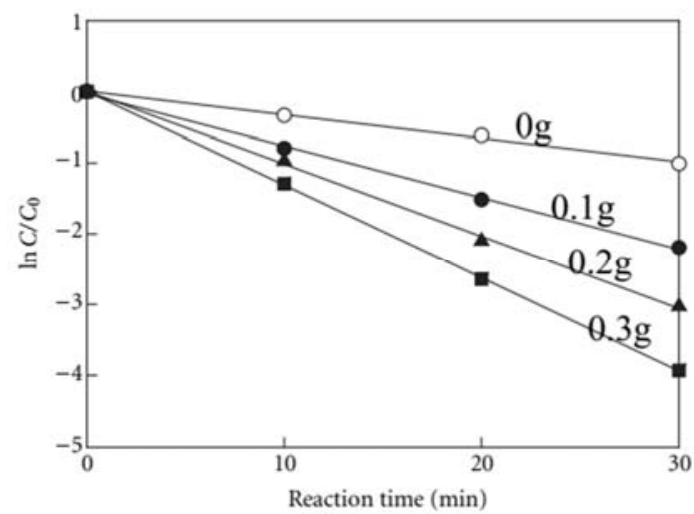

Figure 18. Effect of $\mathrm{TiO}_{2}$ particle dosages for decomposition of methylene blue in aqueous solutions.

\subsubsection{Effects of Scavengers on Photocatalysis}

Over the past 10 years, research has focused on enhancing the performance of photocatalysis by applying various techniques, including the surface modification of the photocatalyst, and adding an scavengers such as $\mathrm{AgNO}_{3}$, $\mathrm{CH}_{3} \mathrm{OH}, \quad \mathrm{KBrO}_{3}, \quad\left(\mathrm{NH}_{4}\right)_{2} \mathrm{~S}_{2} \mathrm{O}_{8}, \quad$ EDTA etc. [67]. These scavengers are a chemical substance added to a mixture in order to remove or de-activate impurities and unwanted reaction products [68].

Hou and co-workers presented the effect of free radical scavenger on the degradation of methyl blue dye as indicated in the Figure 19 [69]. Potassium iodide and hole were reduced by the free radical $(\mathrm{OH})$ binding of terephthalic acid to the hydroxyl group $\left(\mathrm{h}^{+}\right)$. The activity of the catalyst was reduced. The Quinone could be combined with a superoxide free radical $\left(\mathrm{O}_{2}^{-}\right)$to reduce the activity of the catalyst. When the methylene blue was degraded, the addition of Quinone was obviously better than the addition of potassium iodide and terephthalic acid, indicating that hydroxyl radicals and holes play a leading role in photocatalysis.

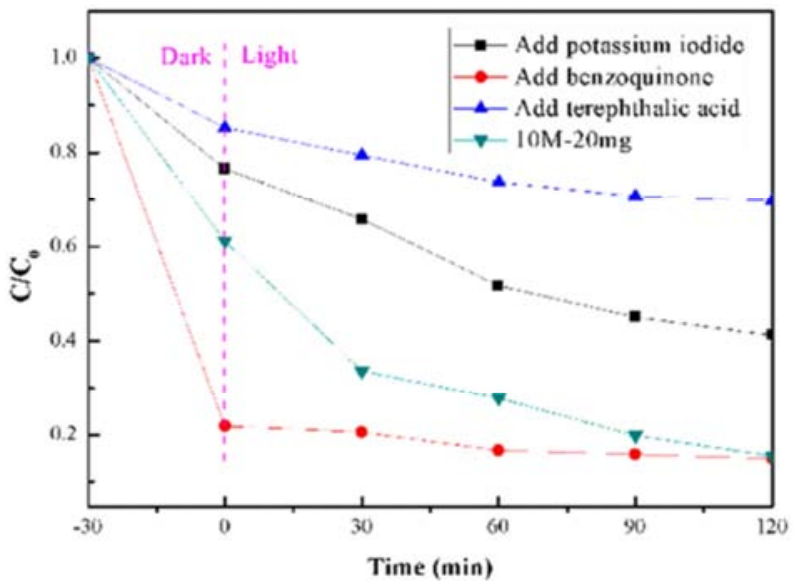

Figure 19. Degradation diagram of the prepared samples for methylene blue in the presence of different scavengers. 


\section{Conclusions and Future Perspectives of Nanophotocatalyst}

Majority of the studies reveals that different supporting materials (such as conductive polymers) act as effective sensitizers for $\mathrm{TiO}_{2}$. However, the overall performance of conducting polymer sensitized $\mathrm{TiO}_{2}$ nanocomposite is dependent upon several critical structural parameters. Among these the efficiency of the separation of photogenerated electrons should be sensitively varied by the interfacial interactions between the polymer and the oxide substrates. The structures of the dye molecules also affect the electron transfer dynamics at the interface between the dye and the nanocomposite surface. This review demonstrated that conductive polymers are useful to improve the performance of composite photocatalysts for photocatalytic degradation of hazardous chemicals, focusing on the roles of conductive polymers.

Doping with various metal species and coupling with other oxide semiconductors are also possible solving routes to increase the lifetime of the photo-produced electron-hole pairs and improvement of the photocatalytic activity of Titania. The negatively charged inorganic anions in wastewaters behaved like to $\mathrm{h}^{+}$and ${ }^{\circ} \mathrm{OH}$ scavengers and cause a negative effect on the photocatalytic processes. Whereas the dissolved metal ions in wastewaters and inorganic oxidants increase the electron-hole separation time, by accepting the conduction band electron and resulting in the improvement of the photocatalytic activity of Titania.

This supported $\mathrm{TiO}_{2}$ photocatalysts are not only highly effective under visible and/or solar light but can also be reused for multiple-runs without any significant loss in photocatalytic activity. The operational parameters like $\mathrm{pH}$, catalyst loading, dye concentration, light intensity and calcination temperature also be considered. For this a successful collaboration of chemical engineers and chemists is required which would provide better insight and solutions to issues that are hindering commercialization of supported $\mathrm{TiO}_{2}$ photocatalysts. The nanocomposites preparation by using carboneous material, polymer and ceramic materials are still in initial stage. So, we need to focus for developing more reliable photocatalysts which can absorb visible and solar radiation or by both.

\section{Conflicts of Interest}

The authors declared that they have no conflicts of interest.

\section{Acknowledgements}

The authors are grateful to the Department of Chemistry, Haramaya University, Ethiopia, for their constantly supporting our research program on nanomaterials, especially their encouragement and genuine support on the knowledge of nanotechnology by preparing different work shop schedules.

\section{References}

[1] Akpan, U. and Hameed, B. 2009. Parameters affecting the photocatalytic degradation of dyes using $\mathrm{TiO}_{2}$ based photocatalysts. Journal of Hazardous Materials, 170: 520-529.

[2] Jalil, A. A., Adam, S. H., Rahim, N. D., Arif, M., Aziz, A., Hanis, N., Hairom, H. and Khairul, N. M. 2010. Adsorption of methyl orange from aqueous solution onto calcined Lapindo volcanic mud. Journal of Hazardous Materials, 181: 755-762.

[3] Puzyn, T. 2012. Organic pollutants ten years after the Stockholm convention. Environmental and Analytical Update.

[4] Rajamohan, N. 2009. Equilibrium studies on sorption of an anionic dye onto acid activated water hyacinth roots. African Journal of Environmental Science and Technology, 3 (11): 399-404.

[5] Hathway, T. 2009. Titanium dioxide photocatalysis: studies of the degradation of organic molecules and characterization of photocatalysts using mechanistic organic chemistry. Journal of Photochemistry and Photobiology A, 200 (2): 216-224.

[6] Sathishkumar, P., Pugazhenthiran, N., Mangalaraj, R., Asiri, A and Anandan, S. 2013. $\mathrm{ZnO}$ supported $\mathrm{CoFe}_{2} \mathrm{O}_{4}$ nanophotocatalyst for the mineralization of Direct Blue in aqueous environments. Journal of Hazardous Materials, 252253: $171-179$.

[7] Konstantinou, I. K. and Albanis, T. A. 2004. $\mathrm{TiO}_{2}$-assisted photocatalytic degradation of azo dyes in aqueous solution: kinetic and mechanistic investigations: a review. Applied Catalysis B, 49: 1-14.

[8] Ullah, I., Ali, S., Hanif, M. and Shahid, S. 2012. Nanoscience for environmental remediation: A Review. International Journal of Chemical and Biochemical Sciences, 2: 60-77.

[9] Ni, M., Leung, M. K. H., Leung, D. Y. C. and Sumathy, K. 2007. A review and recent developments in photocatalytic water-splitting using $\mathrm{TiO}_{2}$ for hydrogen production. Journal of Renewable and Sustainable Energy Reviews, 11: 401-425.

[10] Pekakis, P. A., Xekoukoulotakis, N. P. and Mantzavinos, D. 2006. Treatment of textile dye house wastewater by $\mathrm{TiO}_{2}$ photocatalysis. Water Reserved, 40 (6): 1276-1286.

[11] Hassan, M. E., Chen, J., Liu, G., Zhu, D. and Cai, J. 2014. Enhanced photocatalytic degradation of methyl orange dye under the daylight irradiation over $\mathrm{CN}-\mathrm{TiO}_{2}$ modified with OMS-2. Materials, 7: 8024-8036.

[12] Li, X., Wang, X., Cheng, G., Luo, Q., An, J. and Wang, Y. 2008. Preparation of polyaniline- modified $\mathrm{TiO}_{2}$ nanoparticles and their photocatalytic activity under visible light illumination. Applied Catalysis, B, 81 (3-4): 267-273.

[13] Rao, C. N. R., Muller, A. and Cheetham, A. K. 2004. The Chemistry of Nanomaterials: Synthesis, Properties and Applications Willey, Weinheim.

[14] Bandyopadhyay, A. K. 2008. Nano Materials: in architecture, interior architecture and design, New Age International, New Delhi.

[15] Chaudhuri, R. G. and Paria, S. 2012. Core/shell nanoparticles: Classes, properties, synthesis mechanisms, characterization, and applications. Chemical Reviews, 112: 2373-433. 
[16] Gao, S., Wang, W., Ni, Y., Lu, C. and Xu, Z. 2015. Facetdependent photocatalytic mechanisms of anatase $\mathrm{TiO}_{2}$ : a new sight on the self-adjusted surface heterojunction. Journal of Alloys Compound, 647: 981-8.

[17] Han, X., Kuang, Q., Jin, M., Xie, Z. and Zheng, L. 2009. Synthesis of Titania nanosheets with a high percentage of exposed (001) facets and related photocatalytic properties. Journal of American Chemical Society, 131: 3152-3.

[18] Fu, J., Cao, S. and Yu, J. 2015. Dual Z-scheme charge transfer in $\mathrm{TiO}_{2}-\mathrm{Ag}-\mathrm{Cu}_{2} \mathrm{O}$ composite for enhanced photocatalytic hydrogen generation. Journal of Material, 1: 124-133.

[19] Abi M. Taddesse., Tigabu Bekele., Isabel Diaz. and Abebaw Adgo. 2021. Polyaniline supported $\mathrm{CdS} / \mathrm{CeO}_{2} / \mathrm{Ag}_{3} \mathrm{PO}_{4}$ nanocomposite: An "A-B" type tandem n-n heterojunctions with enhanced photocatalytic activity. Journal of Photochemistry and Photobiology, A: Chemistry, 406: 113005.

[20] Ananpattarachai, J., Kajitvichyanukul, P. and Seraphin, S. 2009. Visible light absorption ability and photocatalytic oxidation activity of various interstitial N-doped $\mathrm{TiO}_{2}$ prepared from different nitrogen dopants. Journal of Hazardous Materials, 168: 253-261.

[21] Liu, Y., Ohko, Y., Zhang, R., Yang, Y. and Zhang, Z. 2010. Degradation of malachite green on $\mathrm{Pd} / \mathrm{WO}_{3}$ photocatalysts under solar light. Journal of Hazardous Materials, 184: 386-391.

[22] Bonde, S. R., Rathod, D. P., Ingle, A. P., Ade, R. B., Gade, A. K. and Rai, M. K. 2012. Murraya koenigii-mediated synthesis of silver nanoparticles and its activity against three human pathogenic bacteria. Nano Science Methods, 1:25-36.

[23] Munnik, P., Petra, E., de-Jongh. and Krijn, P. 2015. Recent developments in the synthesis of supported catalysts. Chemical Reviews, 115: 6687-671.

[24] Carp, O., Huisman, C. L. and Reller, A. 2004. Photoinduced reactivity of titanium dioxide. Progress in Solid State Chemistry, 32: 33-177.

[25] Chauhan, R. P. S., Gupta, C. and Prakash, D. 2012. Methodological advancements in green nanotechnology and their applications in biological synthesis of herbal nanoparticles. International Journal of Bioassays, 1 (7): 6-10.

[26] Gupta, V., Gupta, A. R. and Kant, V. 2013. Synthesis, characterization and biomedical application of nanoparticles. Science International, 1 (5): 167-174.

[27] Bootz, A., Vogel, V., Schubert, D. and Kreuter, J. 2004. Comparison of scanning electron microscopy, dynamic light scattering and analytical ultracentrifugation for the sizing of poly (butyl cyanoacrylate) nanoparticles. European Journal of Pharmaceutics and Biopharmaceutics, 57: 369-75.

[28] Escobedo, A. M., Sanchez, E. M. and Pal, U. 2007. Use of diffuse reflectance spectroscopy for optical characterization of unsupported nanostructures. Journal of Optical Materials, 53 (5): 18-22.

[29] Klaas, J., Schulz-Ekloff, G. and Jaeger, N. I. 1997. UVVisible diffuse reflectance spectroscopy of Zeolite-hosted mononuclear Titanium oxide species. Journal of Physical Chemistry, 101 (8): 1305-1311.

[30] Silverstein, R. M. and Webster, F. X. 2002. Spectrometric identification of organic compounds, $6^{\text {th }}$ edition. Jhon Wiley and Sons, New York.
[31] Lefebvre, J., Austing, D. G., Bond, J. and Finnie, P. 2006. Photoluminescence imaging of suspended single-walled carbon nanotubes. Nano Letters, 6: 1603-1608.

[32] Tao, T., Zhu, S., Feng, T., Xia, C., Song, Y. and Yang, B. 2017. The polymeric characteristics and photoluminescence mechanism in polymer carbon dots. Materials Today Chemistry, 6: 13-25.

[33] Riaz, U., Ashraf, S. M. and Aqib, M. 2014. Microwave-assisted degradation of acid orange using a conjugated polymer, polyaniline, as catalyst. Arabian Journal Chemistry, 7 (1): 79-86.

[34] Kumar, R. V., Diamant, Y. and Gedanken, A. 2000. Sonochemical synthesis and characterization of nanometersize transition metal oxides from metal acetates. Chemical Materials, 12: 2301- 2305.

[35] Rannou, P. and Pron, 2002. Investigation of the electrochromic properties of tri-block polyanilinepolythiophene-polyaniline under visible light. Progress Polymer Science, 27: 135.

[36] Liao, G., Chen, S., Quan, X., Zhang, Y. and Zhao, H. 2011. Remarkable improvement of visible light photocatalysis with PANI modified core-shell mesoporous $\mathrm{TiO}_{2}$ microspheres. Applied Catalysis B: Environmental, 102: 126-131.

[37] Zhang, X., Sun, D. D., Li, G. and Wanga, Y. 2008. Investigation of the roles of active oxygen species in photodegradation of azo dye $\mathrm{AO} 7$ in $\mathrm{TiO}_{2}$ photocatalysis illuminated by microwave electrode less lamp. Journal of Photochemical and Photobiology A, 199: 311-315.

[38] Sangareswari, M. and Sundaram, M. M. 2017. Development of efficiency improved polymer- modified $\mathrm{TiO}_{2}$ for the photocatalytic degradation of an organic dye from wastewater environment. Application of Water Science, 7: 1781-1790.

[39] Xu, S., Jiang, L., Yang, H., Song, Y. and Dan, Y. 2011. Structure and photocatalytic activity of polythiophene/ $/ \mathrm{TiO}_{2}$ composite particles prepared by photoinduced polymerization. Chinese Journal of Catalysis, 32 (4): 536-545.

[40] Pelaez, M., Nolan, N. T., Pillai, S. C., Seery, M. K., Falaras, P., Kontos, A. G., Dunlop, P. S. M., Hamilton, J. W. J., Byrne, J. A., O'Shea, K., Entezari, M. H. and Dionysiou, D. D. 2012. A review on the visible light active titanium dioxide photocatalysts for environmental applications. Applied Catalysis B: Environmental B, 125: 331-349.

[41] Castro, A. L., Nunes, M. R., Carvalho, M. D., Ferreira, L. P., Jumas, J. C., Costa, F. M. and Florencio, M. H. 2009. Doped titanium dioxide nanocrystalline powders with high photocatalytic activity. Journal of Solid State Chemistry, 182 (7): 1838-1845.

[42] Murcia, J. J., Guarin, J. R., Cely, A. C., Rojas, H. A., Cubillos, J. A., Hidalgo, M. C. and Navio. J. A. 2017. Methylene blue degradation over $\mathrm{M}-\mathrm{TiO}_{2}$ photocatalysts $(\mathrm{M}=\mathrm{Au}$ or $\mathrm{Pt})$. Developing Science, 8 (1): 109-117.

[43] Mills, A., Hunte, A. J. 1997. An overview of semiconductor photocatalysis. Journal of Photochemistry and Photobiology, A Chemical, 108: 1-35.

[44] Kumar, S. G. and Devi, L. G. 2011. Review on modified $\mathrm{TiO}_{2}$ photocatalysis under UV/visible light: Selected results and related mechanisms on interfacial charge carrier transfer dynamics. Journal of Physical Chemistry, A. 115 (46): 13211-13241. 
[45] Liu, L., Ji, Z., Zou, W., Gu, X., Deng, Y., Gao, F., Tang, C. and Dong, L. 2013. In Situ loading transition metal oxide clusters on $\mathrm{TiO}_{2}$ Nanosheets as Co-catalysts for exceptional high photoactivity. American Chemical Society Catalysis, 3 (9): 2052-2061.

[46] Eskandarloo, H., Badiei, A. and Behnajady, M. A. 2014. $\mathrm{TiO}_{2} / \mathrm{CeO}_{2}$ hybrid photocatalyst with enhanced photocatalytic activity. Optimization of Synthesis Variables. Industrial and Engineering Chemistry Research, 53: 7847-7855.

[47] Arques, A., Amat, A. M., Juanes, L. S., Vercher, R. F., Marin, M. L. and Miranda, M. A. 2007. Sepiolites as supporting material for organic sensitizers employed in heterogeneous solar photocatalysis. Journal of Molecular Catalysis A: Chemical, 271: 221-226.

[48] Bhattacharyya, A., Kawi, S. and Ray, M. B. 2004. Photocatalytic degradation of orange II by $\mathrm{TiO}_{2}$ catalysts supported on adsorbents. Catalysis Today, 98: 431-439.

[49] Mogyorosi, K., Farkas, A. and Dekany, I. 2002. $\mathrm{TiO}_{2}$-based photocatalytic degradation of 2- Chlorophenol adsorbed on hydrophobic clay. Environmental Science and Technology, 36: 3618-3624.

[50] Sun, Z., Chen, Y., Ke, Q., Yang, Y. and Yuan, J. 2002. Photocatalytic degradation of a cationic azo dye by $\mathrm{TiO}_{2} /$ bentonite nanocomposite. Journal of Photochemistry and Photobiology, A Chemistry, 149: 169-174.

[51] Xie, Z. M., Chen, Z. and Dai, Y. Z. 2009. Preparation of $\mathrm{TiO}_{2} /$ sepiolite photocatalyst and its application to printing and dyeing wastewater treatment. Environmental Science and Technology, 32: 123-127.

[52] Kun, R., Mogyorosi, K. and Dekany, I. 2006. Synthesis and structural and photocatalytic properties of $\mathrm{TiO}_{2} /$ montmorillonite nanocomposites. Applied Clay Science, 32: 99-110.

[53] Fukahori, S., Ichiura, H., Kitaoka, T. and Tanaka, H. 2003. Capturing of bisphenol A photodecomposition intermediates by composite $\mathrm{TiO}_{2} /$ zeolite sheets. Applied Catalysis B: Environmental, 46: 453-462.

[54] Chong, M. N., Vimonses, V., Lei, S., Jin, B., Chow, C. and Saint, C. 2009. Synthesis and characterization of novel Titania impregnated kaolinite nanophotocatalyst. Microporus and Mesoporous Material, 117: 233-242.

[55] Li, X., Peng, K., Chen, H. and Wang, Z. 2018. $\mathrm{TiO}_{2}$ nanoparticles assembled on kaolinites with different morphologies for efficient photocatalytic performance. Scientific Reports, 8: 11663.

[56] Shi, Y., Hu, Y., Zhang, L., Yang, Z., Zhang, Q., Cui, H., Zhu, X., Wang, J., Chen, J. and Wang, K. 2017. Palygorskite supported $\mathrm{BiVO}_{4}$ photocatalyst for tetracycline hydrochloride removal. Applied Clay Science, 137: 249-258.

[57] Chiang, Y. J. and Lin, C. C. 2013. Photocatalytic decolorization of methylene blue in aqueous solutions using coupled $\mathrm{ZnO} / \mathrm{SnO}_{2}$ photocatalysts. Powder Technology, 246: 137-143.

[58] Karunakaran, C. and Dhanalakshmi, R. 2008. Semiconductorcatalyzed degradation of phenols with sunlight. Solar Energy Materials and Solar Cells, 92 (11): 1315-1321.

[59] Nasikhudin, Diantoro, M., Kusumaatmaja, A. and Triyana, K. 2018. Study on photocatalytic properties of $\mathrm{TiO}_{2}$ nanoparticle in various pH conditions. Journal of Physics, 1011: 012069.

[60] Daneshvar, N., Salari, D. and Khataee, A. R. 2003. Photocatalytic degradation of azo dye acid red 14 in water: investigation of the effect of operational parameters. Journal of Photochemistry and Photobiology A, 157: 111-116.

[61] Saggioro, E. M., Oliveira, A. S., Pavesi, T., Maia, C. G., Ferreira, L. F. V. and Moreira, J. C. 2011. Use of titanium dioxide photocatalysis on the remediation of model textile wastewaters containing azo dyes. Molecules, 16: 10370-10386.

[62] Hadjltaief, H. B., Omri, A., Zina, M. B., Costa, P. and Galvez, M. E. 2015. Titanium dioxide supported on different porous materials as photocatalyst for the degradation of methyl green in wastewaters. Advances in Materials Science and Engineering, 10 : 759853. http://dx.doi.org/10.1155/2015/759853.

[63] Venkatachalam, N., Palanichamy, M., Arabindoo, B. and Murugesan, V. 2007. Enhanced photocatalytic degradation of 4-chlorophenol by $\mathrm{Zr}^{4+}$ doped nano $\mathrm{TiO}_{2}$. Journal of Molecular Catalysis A: Chemical, 266 (1-2): 158-165.

[64] Gaya, U. I. and Abdullah, A. H. 2008. Heterogeneous photocatalytic degradation of organic contaminants over titanium dioxide: a review of fundamentals, progress and problems. Journal of Photochemistry and Photobiology C: Photochemistry Revision, 9: 1-12.

[65] Chen, C. C., Lu, C. S., Chung, Y. C. and Jan, J. L. 2007. UV light induced photodegradation of malachite green on $\mathrm{TiO}_{2}$ nanoparticles. Journal of Hazardous Material, 141: 520-528.

[66] Lee, H., Park, S. H., Kim, B. H., Kim, S. J., Kim, S. C., Seo, S. G. and Jung, S. C. 2012. Contribution of dissolved oxygen to methylene blue decomposition by hybrid advanced oxidation processes system. International Journal of Photoenergy, 6: 305989.

[67] Ahmed, F., Kumar, S., Arshi, N., Anwar, M. S., Su-Yeon, L., Sukil, G., Wonpark, D., Koo, B. H. and Lee, C. G. 2011. Preparation and characterizations of $\mathrm{PANI} / \mathrm{ZnO}$ nanocomposite film using solution casting method. Thin Solid Films, 519: 8375-837.

[68] Pera, M., Garcia-Molina, V., Banos, M. A., Gimenez, J. and Esplugas, S. 2004. Degradation of chlorophenols by means of advanced oxidation processes: a general review. Applied Catalysis B: Environmental, 47: 219-256.

[69] Hou, C., Hu, B. and Zhu, J. 2018. Photocatalytic degradation of methylene blue over $\mathrm{TiO}_{2}$ pretreated with varying concentrations of $\mathrm{NaOH}$. Catalysts, 8: 575. 